\title{
Small Vessel Angioplasty
}

\author{
Lalita Nemani ${ }^{1}$ \\ ${ }^{1}$ Department of Cardiology, Nizam's Institute of Medical Sciences, \\ Punjagutta, Hyderabad, Telangana, India
}

Indian J Cardiovasc Dis Women-WINCARS 2017;2:111-118

\section{Introduction}

The term "small vessel" denotes a coronary artery with reference vessel diameter (RVD) $<2.8$ to $3.0 \mathrm{~mm} .{ }^{1}$ Lesions involving small vessels account for 40 to $50 \%$ of all coronary stenosis. ${ }^{2}$ Revascularization of these vessels is impeded by high technical failure in coronary artery bypass grafting (CABG) and increased risk of adverse events and restenosis with percutaneous coronary intervention (PCI). Intervention in small coronary vessels constitutes 30 to $50 \%$ of all intervention procedures performed worldwide every year. ${ }^{3-5}$

The arbitrary upper limit of lumen diameter is between 2.5 and $2.75 \mathrm{~mm}$. However, with the availability of 2.25- and 2-mm-diameter stents, the term "very small vessel disease" has been suggested to lesions that are amenable to PCI with these devices. $\mathrm{PCI}$ in these vessels is considered controversial because (1) these vessels perfuse a small territory and may not be worth stenting, (2) they have a higher risk of dissection, perforation, and restenosis, and (3) they are technically more challenging in terms of lesion crossability. The decision to stent these vessels should be interpreted with the clinical scenario of the patient in mind.

\section{Uniqueness of Small Vessel Disease and Intervention}

Patients with lesions in small vessels constitute a distinct population. Their clinical characteristics include more women, elderly, associated diabetes mellitus, heart failure, and peripheral vascular disease. Lesions tend to be more complex and more commonly multivessel, and frequently are American College of Cardiology/American Heart Association (ACC/AHA) type $\mathrm{C}$ lesions. Intervention of these vessels is a challenge for any interventional cardiologist. Lesions are frequently located distally, and negotiation of stent is hampered by the distal location of lesion, tortuosity, and calcium. Disease is more diffuse requiring longer stents to cover the entire segment. Small vessel lumen size leaves little space for error in sizing and stent expansion. This limits the stent option availability (type, length, diameter, and drug) for these vessels. Long-term results are even more disappointing despite
Address for correspondence Lalita Nemani, MD, DM, Department of Cardiology, Nizam's Institute of Medical Sciences, Punjagutta, Hyderabad, Telangana 500082, India (e-mail: drlalita775@gmail.com).

satisfactory initial deployment. Small coronary vessel angioplasty is an independent predictor of repeat revascularization and adverse cardiac events. ${ }^{6,7}$

\section{Accurate Assessment of Vessel Diameter}

As small vessels pose many technical difficulties during $\mathrm{PCI}$, it is essential to confirm that the vessel is really small as it appears angiographically. Vasoconstriction could be a possibility; hence, vessel size should be reassessed after administration of $200 \mu \mathrm{g}$ of nitroglycerine intracoronary. Intravascular ultrasound (IVUS) would be useful in assessing the correct luminal diameter. If IVUS is not available, computer-assisted quantitative coronary angiography is recommended to assess vessel diameter more accurately.

\section{Ideal Treatment of Choice in Small Vessels}

Percutaneous treatment of coronary artery disease (CAD) has evolved from plain old balloon angioplasty (POBA) to bare metal stent (BMS) and more recently to drug-eluting stent (DES) implantation, and drug-eluting balloons. Large randomized clinical trials have established large coronary vessels ( $>3 \mathrm{~mm}$ ) as a definite indication for stenting. However, there are no well-defined recommendations regarding the intervention of choice for small coronary vessels

\section{Bare Metal Stent versus Balloon Angioplasty}

PCIs with BMS as compared with POBA in small vessel disease have shown conflicting results with only modest superiority of BMS over POBA (Park et al, 2000; Kastrati et al, 2000; Koning et al 2001). BMS is also associated with a higher risk of in-stent restenosis.

A meta-analysis of 13 studies was performed by Agostoni et al. ${ }^{8}$ These studies involved 4,383 patients, of whom 2,097 were randomized to percutaneous transluminal coronary angioplasty (PTCA) and 2,286 to stenting with a follow-up for 6 to 16 months. Stenting appears safe in small vessel CAD and significantly reduces angiographic restenosis and repeat revascularization rates. Optimal PTCA group (diameter stenosis
DOI https://doi.org/ 10.1055/s-0038-1624066.
Copyright @2017 Women in Cardiology and Related Sciences
License terms

(®) $\Theta \circledast$ 
$<20 \%$ ) also achieved results comparable to BMS implantation. It was concluded that revascularization rates remain high with PTCA or BMS implantation in patients with small vessel CAD.

\section{Drug-Eluting Stent versus Bare Metal Stent}

The drug-eluting stent (DES) technology has undoubtedly reduced the risk of in-stent restenosis in large vessels, that is, $\geq 3-\mathrm{mm}$ vessels. However, the incorporation of various drugs on the stent platform leads to an increase in effective strut thickness. Hence, the usage of DES in small vessel may pose technical issues in term of stent flexibility and deliverability and a continued risk of late and very late stent thrombosis.

\section{Paclitaxel-Eluting Stent versus Bare Metal Stent}

The TAXUS (Paclitaxel-Eluting Stents in Coronary Artery Disease) subgroup analysis showed that paclitaxel-eluting stent (PES) offers clinical benefits in patients with small vessels compared with BMS. This is mainly attributed to marked inhibition of neointimal hyperplasia by paclitaxel.

In TAXUS IV trial, ${ }^{9}$ vessels with RVD $<2.5 \mathrm{~mm}$ were included and randomized to PES and BMS. Angiographic restenosis rate and 12-month TLR rate in the PES group were significantly lower than those in the BMS group, (10.2\% and 5.6\% vs. $38.5 \%$ and 20.6\%; $p<0.001$ ).

In the TAXUS $\mathrm{V}$ trial, ${ }^{10}$ patients treated with $2.25-\mathrm{mm}$ stent were followed. Both PES and BMS have similar acute outcomes. The angiographic restenosis rates and TLR rates were significantly lower in PES group as compared with BMS group (31\% and $10.4 \%$ vs. $49.4 \%$ and $21.5 \% ; p=0.01$ and $p=0.03$, respectively). However, 9-month major adverse cardiac event (MACE) rates were $18.9 \%$ versus $26.9 \%$; $p=0.23$, which did not reach statistical significance.

In the TAXUS VI trial ${ }^{11}$ that included vessels with RVD $<2.5 \mathrm{~mm}$, in-stent late lumen loss was considerably smaller in the PES group than in the BMS group $(0.23 \pm 0.45 \mathrm{~mm}$ vs. $0.95 \pm 0.52 \mathrm{~mm} ; p<0.0001)$ at 9 months explaining the significantly lower angiographic restenosis and target lesion revascularization (TLR) observed in the PES group (7.3\% and $5.0 \%$ vs. $40.4 \%$ and $29.7 \%$, respectively; $p=0.001$ ).

\section{Sirolimus-Eluting Stent versus Bare Metal Stent}

In the substudy of SIRIUS (SIRolImUS-Eluting Stent in De Novo Native Coronary Lesions) trial, ${ }^{12}$ sirolimus-eluting stent (SES) in small vessels $(<2.75 \mathrm{~mm})$ was associated with lower TLR rates (6.6\% vs. 22.3\%; $p<0.0001)$ and lower angiographic restenosis rates ( $17.6 \%$ vs. $42.7 \% ; p<0.001$ ) when compared with BMS.

The incidence of TLR and MACE was significantly lower in the SES group (7.0\% and $9.3 \%$ vs. $21.1 \%$ and $31.3 \%$; $p=0.002$ and $p<0.001$ ), and so it was the angiographic restenosis rates (9.8\% vs. 53.1\%, $p<0.001)$ compared with BMS in the SES-SMART (Sirolimus-Eluting Stent and a Standard Stent in the Prevention of Restenosis in Small Coronary Arteries) trial, ${ }^{13}$ which enrolled small vessels with $\mathrm{RVD}=2.2 \mathrm{~mm}$.

SES versus PES: SES definitely proved better than PES in small vessels in terms of angiographic restenosis, TLR, and MACE. This was proved in the ISAR-SMART (Intracoronary Stenting or Angioplasty for Restenosis Reduction in Small Arteries), ${ }^{14}$ Park et $\mathrm{al}^{15}$ retrospective analysis, and also the subgroup analysis of SIRTAX (Sirolimus-Eluting Versus Paclitaxel-Eluting Stents for Coronary Revascularization) trial. ${ }^{16}$

Zotarolimus-eluting stent (ZES) versus PES: There was significantly less target vessel failure at 12 months with ZES compare with PES (8.3\% vs. $13.4 \%$; odds ratio $[\mathrm{OR}]=0.62 ; 95 \%$ confidence interval [CI]: $0.37-1.03$ ) in small vessel $<2.5 \mathrm{~mm}$ in the ENDEAVOR (A Randomized, Controlled Trial of the Medtronic Endeavor Drug [ABT-578] Eluting Coronary Stent System Versus the Taxus Paclitaxel-Eluting Coronary Stent System in De Novo Native Coronary Artery Lesions) IV ${ }^{17}$ study. However, no such difference was observed in the 2.5- to 3-mm group.

Everolimus-eluting stent (EES) versus PES: EES scored over PES in terms of lower target vessel failure (3.9\% vs. $6.8 \%$; OR $=0.57 ; 95 \%$ CI: $0.35-0.91)$ in vessels $<2.75 \mathrm{~mm}$ in the SPIRIT (Stroke Prevention in Reversible Ischemia Trial) IV trial. ${ }^{18}$

Biolimus-eluting stent (BES) versus SES: In the substudy of LEADERS (Limus Eluted From A Durable Versus ERodable Stent Coating) trial, ${ }^{19}$ comparing BES with biodegradable polymer and SES with durable polymer; the impact of vessel size on outcomes with these two different stent strategies was assessed. Comparison was done for the vessel size $>2.75 \mathrm{~mm}$ ( $50 \%$ of the total cohort) and $<2.75 \mathrm{~mm}$. There was no significant difference between TLR rate (9.6\% vs. $7.4 \%$; $p=0.26)$ and MACE (12.1\% vs. $11.8 \% ; p=0.89)$ in both BES and SES arms. However, the TLR rate (9.6\% vs. $2.6 \%)$ and MACE (12.7\% vs. $7.1 \%$ ) were significantly higher in small vessels as compared with large vessels in the BES arm.

To summarize, outcome in small vessel stenting has improved considerable with the use of DES. TLR has reduced from 20 to $30 \%$ with BMS to $10 \%$ with DES, which is still considerably high. EES and SES score over PES and ZES in terms of lower TLR (3-7\% vs. 8-13\%) and later lumen loss $(0.14 \pm 0.41 \mathrm{~mm}$ for EES in SPIRIT III trial and $0.16 \pm 0.30 \mathrm{~mm}$ for SES in pivotal trial).

Drug-coated balloon angioplasty (DCBA) evolved as treatment for in-stent restenosis, and it holds promising as standalone therapy for small vessel disease. It has the advantage of short-duration dual antiplatelet therapy (DAPT) and allows positive remodeling of the affected segment in the absence of residual metal. The PICOLETTO (Paclitaxel-Coated Balloon Versus Drug-Eluting Stent During Percutaneous Coronary Intervention of Small Coronary Vessels $)^{20}$ trial, with first-generation DIOR paclitaxel-coated balloon versus PES during PCI of small coronary vessels, failed to show noninferiority of DCB to DES. There was lower TLR in the DES arm (TAXUS Liberte) (10.3\% vs. $32.1 \%$; $p=0.043$ ). In the prospective BELLO (Balloon Elution and Late Loss Optimization) study, paclitaxel DCBA was associated with less 6 months angiographic lumen loss $(0.08$ \pm 0.38 vs. $0.29 \pm 0.44 \mathrm{~mm} ; p$ [noninferiority] < 0.001 ; 
$p$ [superiority] $=0.001)$. Paclitaxel DCBA showed similar rates of restenosis (10\% vs. $14.6 \% ; p=0.35)$ and revascularization ( $4.4 \%$ vs. $7.6 \% ; p=0.37$ ) to paclitaxel-eluting DES in treating small vessel disease. ${ }^{21}$ The prospective PEPCAD $\mathrm{I}^{22}$ (Paclitaxel Eluting PTCA Balloon in Coronary Artery Disease) study showed good 6 months angiographic and 12 months clinical outcome with DCB-only angioplasty in small vessel disease that persisted up to 36 months. The rate of TLR in patients treated only with DCBA was $4.9 \%$ within 12 months.

\section{Outcome of Stenting in Small Vessels}

Arterial diameter and lesion length share an inverse relationship resulting in higher plaque burden in small vessels
(-Fig. 1). Percutaneous revascularization in small vessels is associated with lower rates of procedural success and higher rates of in-hospital major events. Short-term outcome is poor in terms of significant vessel dissection (-Figs. 1-2), vessel spasm ( - Fig. 1) and/or acute vessel closure, myocardial infarction (MI) and emergent coronary bypass grafting, and so is the long-term outcome in terms of restenosis.

Stent thrombosis: DES implantation in small vessels may increase the risk of stent thrombosis; however, this was similar to the stent thrombosis rates seen in large vessels. The incidence of stent thrombosis in small vessel DES implantation has not been shown to differ between PES and BMS or SES (TAXUS-V, ISAR-SMART 3, RESEARCH and T-SEARCH registry, SIRTAX trials). Lee et al ${ }^{23}$ have reported the late stent thrombosis of $0.4 \%$ up to 20 months following
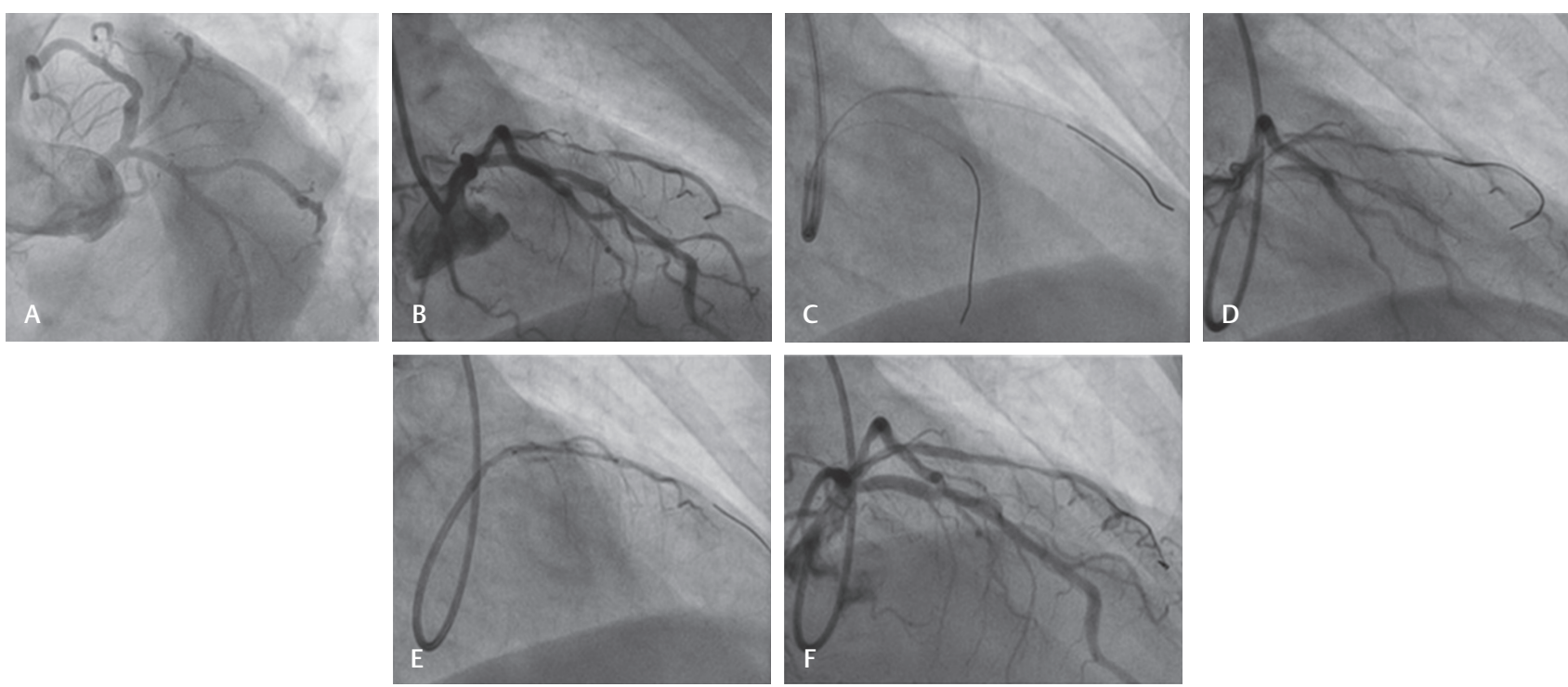

Fig. 1 (A) LAO caudal view showing 90\% stenosis in D1 (diagonal), a 2.25 vessel. (B) RAO cranial 40-40 showing tight stenosis in D1, type B1. (C) Wiring of both LAD and D1 and predilation of D1 lesion with $1.5 \times 15$ balloon at $10 \mathrm{~atm}$. (D) Dissection in proximal D1, spasm of rest of vessel. (E) Stent $2.25 \times 15$ deployed in D1 to cover the dissection. Longer stent to cover the entire lesion could not be negotiated. (F) Final result good with mild uncovered diseased vessel distal to the stent.
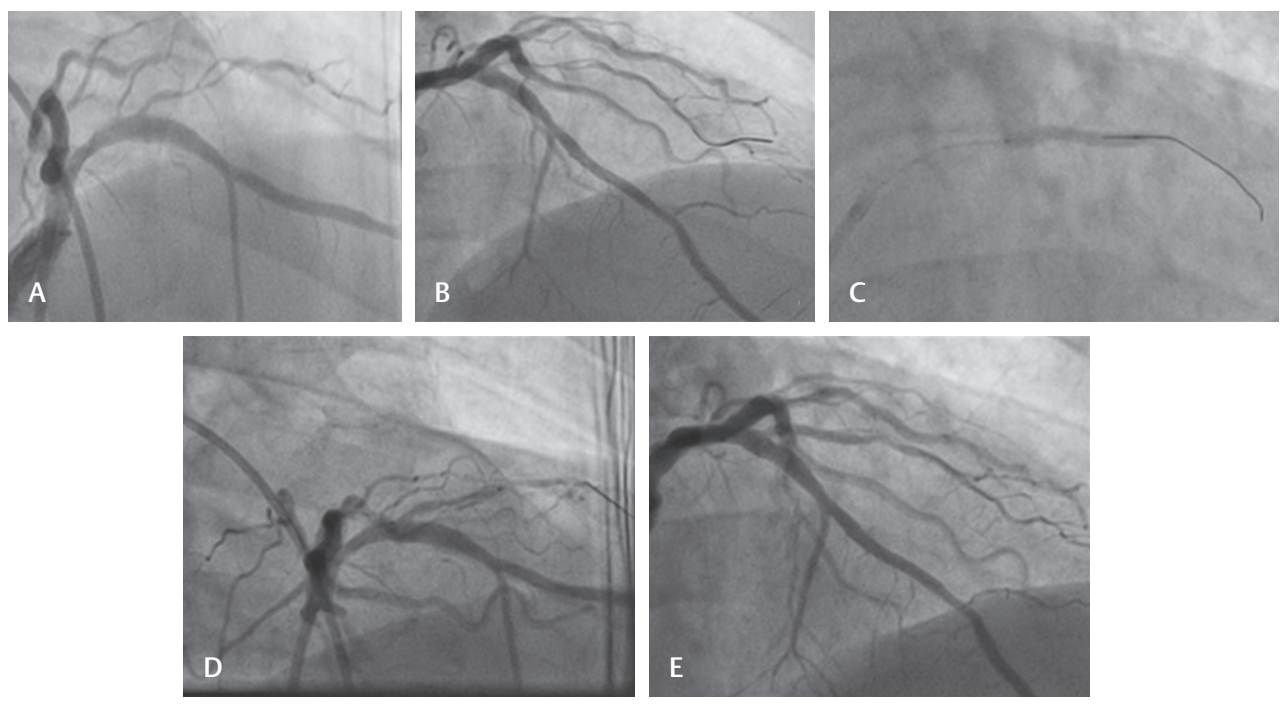

Fig. 2 (A) Diagonal (D1) showing type B2 long-segment tight stenosis ostial-proximal. (B) Wiring of the diagonal with Runthrough guidewire. (C) Predilation with balloon $2 \times 12$ at 6 atm. (D) Dissection of the diagonal seen postdilation. (E) Successful stenting of the vessel covering the dissection. 
SES implantation in small vessels; however, data available are limited.

Restenosis: Small RVD is an independent risk factor for restenosis. The benefit of stenting in small coronaries is a better initial angiographic results, that is, acute lumen gain and minimum luminal diameter (MLD). However, late lumen loss is a major concern. The worse angiographic and clinical outcome is due to higher index loss in smaller vessels despite similar late lumen loss. The restenosis rates with stenting have significantly decreased from 34.2 to $25.8 \%$ ( $8.4 \%$ absolute reduction), though this reduction is lower than that reported for larger vessels $>3 \mathrm{~mm}(10-15 \%)$. This resulted in fewer repeat TLR and better clinical outcome.

The BESMART (BeStent in Small Arteries Trial) ${ }^{24}$ showed that a smaller RVD has a lower relative risk (RR) for restenosis, that is, higher risk reduction following stenting. The higher risk reduction was obtained in vessels 1.5 to $1.9 \mathrm{~mm}$ (70\%, in comparison with $56 \%$ and $50 \%$ in vessels $2-2.4 \mathrm{~mm}$ and $2.5-2.9 \mathrm{~mm}$, respectively). However, contrary results were obtained in the SIRIUS study ${ }^{25}$ in which restenosis risk reduction decreases as RVD decreases. In this study, the restenosis rate for SES and BMS, respectively, was $30.2 \%$ versus $1.9 \%$ (93.7\% risk reduction), $36.5 \%$ versus $6.3 \%$ (82.7\% risk reduction), and $42.9 \%$ versus $18.6 \%$ ( $56.6 \%$ risk reduction) for vessels averaging $3.3 \mathrm{~mm}, 2.8 \mathrm{~mm}$, and $2.3 \mathrm{~mm}$ in RVD, respectively.

Despite these limitations, successful outcome with insignificant complications following small vessel angioplasty and stenting has been reported in many observational studies. Uddin et $\mathrm{al}^{26}$ reported angiographic success rate of $96 \%$ whereas Dan et $\mathrm{al}^{27}$ and Ali et $\mathrm{al}^{28}$ showed $100 \%$ angiographic success. High procedural success rate of $94 \%$ and clinical success rate of $90 \%$ were reported by Rahman et $\mathrm{al}^{29}$ and by Dan et al. ${ }^{27}$

\section{Factors Predictive of Adverse Outcome in Small Vessels}

The risk for major events is particularly high when the small vessel is a proximal or midcoronary segment. The rate of periprocedural major adverse events is sevenfold higher in patients with small proximal left anterior descending arteries than in those with large proximal left anterior descending arteries. This elevated risk is most likely due to the absence of adequate bailout techniques available to treat suboptimal angioplasty results in small vessels. In contrast, a small reference diameter at a distal location is without much clinical significance (-Fig. 3 ).
Lee et $\mathrm{al}^{23}$ have reported significant correlation between restenosis rate and lesion length in small vessels. Multivariate analysis showed that lesion length $(\mathrm{OR}=1.04 ; 95 \%$ CI: $1.02-1.05 ; p<0.001)$ and in-stent restenosis lesions $(\mathrm{OR}=3.38 ; 95 \% \mathrm{CI}: 1.80-6.35 ; p<0.001)$ were significant predictors of restenosis, but not diabetes. Briguori et $\mathrm{al}^{30}$ have shown that strut thickness was an independent predictor of angiographic restenosis in small coronary arteries $($ RVD $=2.75-2.99 \mathrm{~mm})$. Thinner-strutted stents were associated with lower incidence of restenosis than thickerstrutted stents.

\section{Dedicated Stent Designs Proposed for Small Vessels}

Heparin-coated stents: Moer and coworkers ${ }^{31}$ showed that event-free survival was significantly greater in the heparincoated stent group $90.5 \%$ versus $76.1 \%$ in the angioplasty group ( $p=0.15)$. Haude and coworkers, ${ }^{32}$ however, demonstrated improved minimal luminal diameter with heparin- coated stents over balloon angioplasty alone, but there was no difference in major adverse coronary events or restenosis.

Phosphorylcholine (PC)-coated stents: Grenadier and coworkers $^{33}$ and SV stent study demonstrated an acceptably low rate of major coronary events at 6 months with a PC-coated stent BiodivYsio (Abbott Vascular Devices) stent in vessels less than $2 \mathrm{~mm}$. PC is a component of the red cell membrane that is believed to decrease the likelihood of in-stent thrombosis. However, ISAR-SMART-2 showed that PC-coated stents failed to reduce the incidence of angiographic restenosis after $\mathrm{PCI}$ of small coronary arteries.

Thin-strutted stents ( - Fig. 4) were developed to limit vessel wall injury and its sequences. Their uniqueness lies is their improved flexibility and negotiation into distal lesions. The Mini Crown, BeStent (four crowns) (Medtronic), BiodivYsio SV (small vessels), six-cell BxVelocity (Cordis, a Johnson and Johnson Company), Multilink Pixel (Guidant), 2.5-mm Carbostent (Sorin) four-cell, and small vessel Pura Vario AS are designed to fit vessels $<3 \mathrm{~mm}$.

- The ISAR-STEREO-2 trial by Pache and coworkers ${ }^{34}$ showed that thin-strutted Multilink stent (50 $\mu \mathrm{m}$ strut thickness) was clearly superior with a restenosis rate of $17.9 \%$ compared with $31.4 \%$ in the thick-strutted BX velocity stent (140 $\mu \mathrm{m}$ strut thickness). Theoretically, the benefit should be evident in small vessels as well.
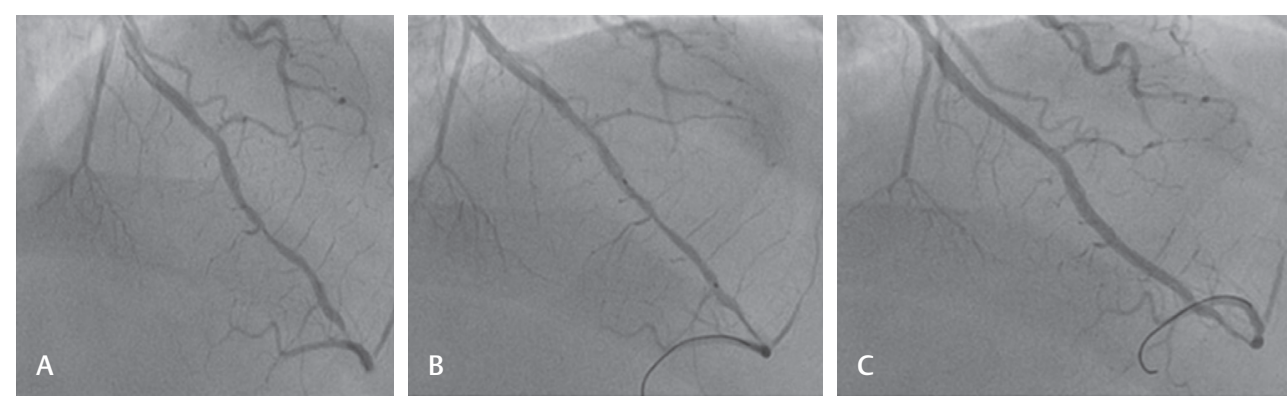

Fig. 3 (A) Ninety percent stenosis of the distal LAD followed by tight stenosis near the apex. (B) Direct stenting with $2.25 \times 20$ DES. (C) Final result good. Distal tight stenosis was left uncovered due to stent size nonmatching. 


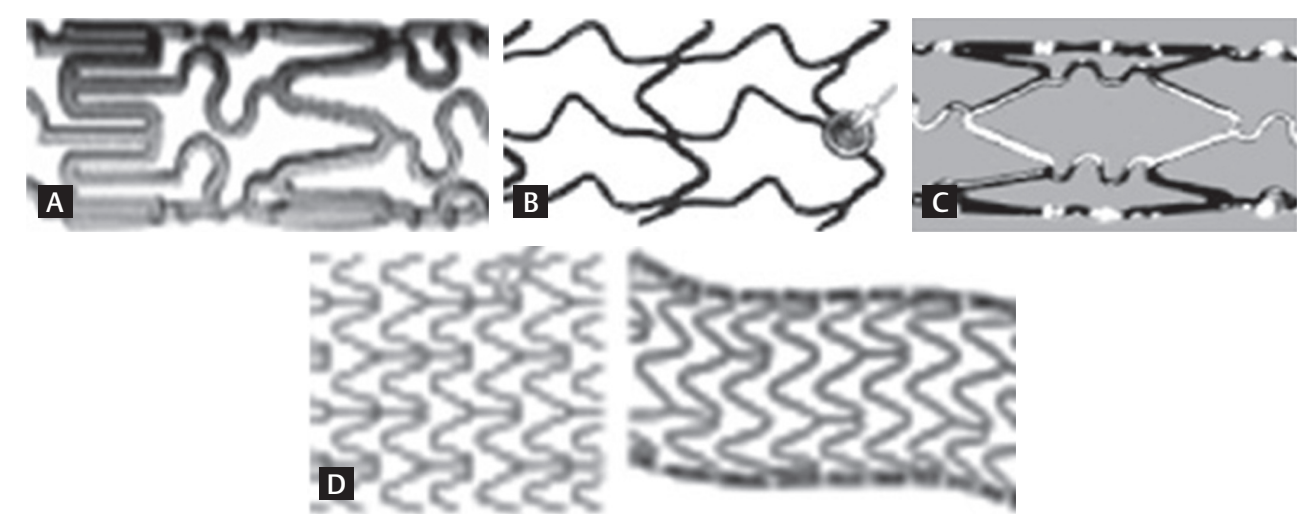

Fig. 4 (A) BiodivYsio SV stent (Abbott Vascular Devices): Balloon-expandable stent made of 316L stainless steel with thickness of 0.0024 in $(0.06 \mathrm{~mm})$ and diameter of $1 \mathrm{~mm}$. Six cells in its circumference, alternating sinusoidal rings consisting of either rectangular or rounded edges linked via two turn (S-shaped) articulations. (B) BeStent (four crown) (Medtronic): Flexible radial "S" crowns and longitudinal "V" crowns crossing at a junction that rotates during expansion with almost no foreshortening. The laser cut stainless steel has two radiopaque gold markers incorporated at the proximal and distal ends. (C) BxVelocity (Cordis, a Johnson and Johnson Company): Sinusoidal ring strut modules linked by flexible "N"-shaped flex segments that reduce foreshortening during expansion. Minimum diameter available is $2.25 \mathrm{~mm}$. Strut width of $0.13 \mathrm{~mm}$ and thickness of $0.14 \mathrm{~mm}$. (D) Multilink RX PIXEL (Guidant): Corrugated Multilink five crown rounded corner zigzag ring module design linked via straight link elements. An additional straight link element is present between modules. Available lengths are 8 to $28 \mathrm{~mm}$ and diameter of 2 to $2.5 \mathrm{~mm}$; strut width of $0.096 \mathrm{~mm}$ and thickness of $0.099 \mathrm{~mm}$.

- In vessels with diameters between 2.75 and $3 \mathrm{~mm}$, Briguori and coworkers ${ }^{30}$ demonstrated significantly less restenosis following stenting with a thin-strutted stent $(p=$ $0.10 \mathrm{~mm}$ ). However, no significant benefit was observed in vessels 2.50 to 2.75 or in those $<2.5 \mathrm{~mm}$.

- Brambilla et $\mathrm{al}^{35}$ have assessed in a prospective, multicenter registry the impact of thin-strutted chrome-cobalt Mini VISION $(0.081 \mathrm{~mm})$ in small coronary vessels. The average RVD was $2.41 \pm 0.41 \mathrm{~mm}$, and the 6-month MACE was $11.6 \%$, death $2.9 \%$, MI $2.9 \%$, and TLR $5.8 \%$ in par with DES.

- TAXUS ATLAS Small Vessel (SV) program is a multicenter study $^{36}$ comparing the performance of the TAXUS Liberte (0.095 mm thin-strutted 2.25-mm stent, Atom; Boston Scientific, Inc.) and TAXUS Express (0.132-mm strut size) stents in small vessels. TAXUS Liberte significantly reduced the rate of 9-month angiographic restenosis (18.5\% vs. $32.7 \% ; p=0.02)$ and 12 -month TLR (6.1\% vs. $16.9 \%$; $p=0.0003)$. This TAXUS Liberte stent was specially designed for small vessels ( $<2.25 \mathrm{~mm}$ ) and was approved by the US Food and Drug Administration (FDA).

- The BiodivYsio SV and BeStent (four crowns) stents are probably the most suitable stents to be implanted on lesions located in small vessels. The stent delivery system of these stents is approximately $0.75 \mathrm{~mm}$ in profile, making them the smallest profile stent delivery system. The Sorin Carbostent is another thin-strutted stent available in a small vessel size. All these stents, with the exception of the BiodivYsio SV stent, are visible under X-ray thanks to distal and proximal radiopaque markers.

- The BxVelocity, with the dedicated six-cell stent, and the Multilink Pixel, a new, small vessel stent by Guidant, are also good choices. In comparison to the other small vessel stents, these two stents do not have thin struts and are visible under X-ray. Garcia ${ }^{37}$ studied then performance of the Pixel stent specifically designed for small vessels. In 350 patients with vessel diameter between 2.2 and
$2.7 \mathrm{~mm}$, procedural success and 6-month outcomes were remarkably good with a low TLR rate.

The design, composition, features of the stent, and stent deployment technique affect strongly the acute performance of the stent, risk of stent thrombosis, degree of vascular response, and subsequent risk of in-stent restenosis. Stent configuration, design, and strut thickness along with DES influence the outcomes in small coronary vessels. The availability of new, highly biocompatible, and more radiovisible alloys with drug elution would improve the anatomical and clinical outcomes of current stainless steel stents. These advanced stents confer several advantages, including thinner stent struts, preserved visibility, and enhanced flexibility. Although registry data for both of these stents have demonstrated excellent performance and clinical outcomes with low TLR rates, there has not yet been any randomized study with these stents in small coronaries.

These data suggest that excellent outcomes can result from using advanced stent technology developed specifically for small vessels.

Resolute Onyx (Medtronic) (-Fig. 5): This is a ZES (2-mm stent) specially designed for small vessels and has recently proved successful for treatment of lesions involving extremely small vessels (RVD from $2 \mathrm{~mm}$ to $2.25 \mathrm{~m}$ ). The first prospective study ${ }^{38}$ of this dedicated size stent has met its primary end with 12-month target lesion failure rate of $5 \%(p<0.001)$ and zero-stent thrombosis and awaits FDA approval.

\section{Conclusion}

Small vessel disease has become common, and the proportion of small vessel interventions are likely to increase. Small vessel angioplasty is and still continues to be a challenge for an interventional cardiologist. Long-term results of BMS stenting in small vessels have been disappointing 


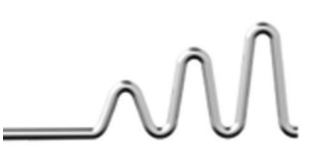

A
Sinusoid-formed wire

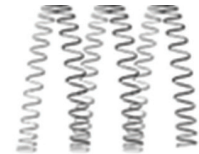

Helical wrap

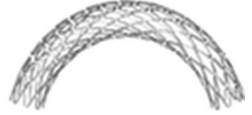

Laser-fused

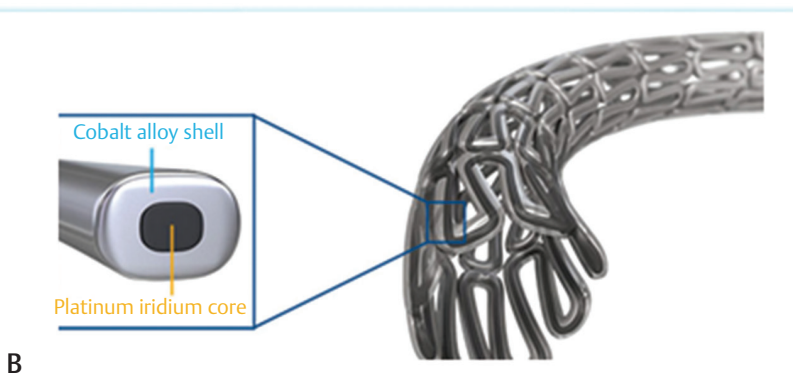

Fig. 5 Resolute Onyx 2.0 MM Coronary Stent (Medtronic). (A) Two stent technologies join forces (continuous sinusoid technology)-a single strand of cobalt alloy is formed into a sinusoid, wrapped in a helical pattern, and laser-fused. Flexible stent platform for outstanding flexibility and conformability (B) Core wire technology-a platinum iridium core within the cobalt alloy shell enhances radiopacity in thinner struts without compromising structural strength. This enhanced visibility ensures accurate stent placement.

and provisional stenting was considered a better option. Advancement in technology, hardware, and pharmacotherapy has changed the scenario of small vessel angioplasty and stenting in recent years. DES has revolutionized the concept of small vessel stenting with reduced angiographic restenosis and TLR and improved clinical outcome. The EES and SES score over PES and ZES with better angiographic and clinical outcome though similar safety profile. DCBA appears promising; however, further large randomized trials are needed to evaluate its role in small vessel CAD. Small vessel interventions can be performed safely with optimal results if caution is adopted.

\section{References}

1 Kastrati A, Schömig A, Dirschinger J, et al. A randomized trial comparing stenting with balloon angioplasty in small vessels in patients with symptomatic coronary artery disease. ISAR-SMART Study Investigators. Intracoronary Stenting or Angioplasty for Restenosis Reduction in Small Arteries. Circulation 2000;102(21):2593-2598

2 Wong P, Lau KW, Lim YL, Oesterle SN. Stent placement for nonSTRESS/BENESTENT lesions: a critical review. Catheter Cardiovasc Interv 2000;51(2):223-233

3 Foley DP, Melkert R, Serruys PW. Influence of coronary vessel size on renarrowing process and late angiographic outcome after successful balloon angioplasty. Circulation 1994;90(3):1239-1251

4 Elezi S, Kastrati A, Neumann FJ, Hadamitzky M, Dirschinger J, Schömig A. Vessel size and long-term outcome after coronary stent placement. Circulation 1998;98(18):1875-1880

5 Akiyama T, Moussa I, Reimers B, et al. Angiographic and clinical outcome following coronary stenting of small vessels: a comparison with coronary stenting of large vessels. J Am Coll Cardiol 1998;32(6):1610-1618

6 Bauters C, Hubert E, Prat A, et al. Predictors of restenosis after coronary stent implantation. J Am Coll Cardiol 1998;31(6):1291-1298
7 Serruys PW, Kay IP, Disco C, Deshpande NV, de Feyter PJ. Periprocedural quantitative coronary angiography after Palmaz-Schatz stent implantation predicts the restenosis rate at six months: results of a meta-analysis of the BElgian NEtherlands Stent study (BENESTENT) I, BENESTENT II Pilot, BENESTENT II and MUSIC trials. Multicenter Ultrasound Stent In Coronaries. J Am Coll Cardiol 1999;34(4):1067-1074

8 Agostoni P, Biondi-Zoccai GG, Gasparini GL, et al. Is bare-metal stenting superior to balloon angioplasty for small vessel coronary artery disease? Evidence from a meta-analysis of randomized trials. Eur Heart J 2005;26(9):881-889

9 Stone GW, Ellis SG, Cox DA, et al; TAXUS-IV Investigators. Oneyear clinical results with the slow-release, polymer-based, paclitaxel-eluting TAXUS stent: the TAXUS-IV trial. Circulation 2004;109(16):1942-1947

10 Stone GW, Ellis SG, Cannon L, et al; TAXUS V Investigators. Comparison of a polymer-based paclitaxel-eluting stent with a bare metal stent in patients with complex coronary artery disease: a randomized controlled trial. JAMA 2005;294(10):1215-1223

11 Dawkins KD, Grube E, Guagliumi G, et al; TAXUS VI Investigators. Clinical efficacy of polymer-based paclitaxel-eluting stents in the treatment of complex, long coronary artery lesions from a multicenter, randomized trial: support for the use of drug-eluting stents in contemporary clinical practice. Circulation 2005;112(21):3306-3313

12 Holmes DR Jr, Leon MB, Moses JW, et al. Analysis of 1-year clinical outcomes in the SIRIUS trial: a randomized trial of a sirolimus-eluting stent versus a standard stent in patients at high risk for coronary restenosis. Circulation 2004;109(5):634-640

13 Ardissino D, Cavallini C, Bramucci E, et al; SES-SMART Investigators. Sirolimus-eluting vs uncoated stents for prevention of restenosis in small coronary arteries: a randomized trial. JAMA 2004;292(22):2727-2734

14 Mehilli J, Dibra A, Kastrati A, Pache J, Dirschinger J, Schömig A; Intracoronary Drug-Eluting Stenting to Abrogate Restenosis in Small Arteries (ISAR-SMART 3) Study Investigators. Randomized trial of paclitaxel- and sirolimus-eluting stents in small coronary vessels. Eur Heart J 2006;27(3):260-266

15 Park KH, Park SW, Hong MK, et al. Comparison of the effectiveness of sirolimus- and paclitaxel-eluting stents for small coronary artery lesions. Catheter Cardiovasc Interv 2006;67(4):589-594

16 Togni M, Eber S, Widmer J, et al. Impact of vessel size on outcome after implantation of sirolimus-eluting and paclitaxel-eluting stents: a subgroup analysis of the SIRTAX trial. J Am Coll Cardiol 2007;50(12):1123-1131

17 Leon MB, Mauri L, Popma JJ, et al; ENDEAVOR IV Investigators. A randomized comparison of the ENDEAVOR zotarolimus-eluting stent versus the TAXUS paclitaxel-eluting stent in de novo native coronary lesions 12-month outcomes from the ENDEAVOR IV trial. J Am Coll Cardiol 2010;55(6):543-554

18 Stone GW, Rizvi A, Newman W, et al; SPIRIT IV Investigators. Everolimus-eluting versus paclitaxel-eluting stents in coronary artery disease. N Engl J Med 2010;362(18):1663-1674

19 Wykrzykowska JJ, Serruys PW, Onuma Y, et al. Impact of vessel size on angiographic and clinical outcomes of revascularization with biolimus-eluting stent with biodegradable polymer and sirolimus-eluting stent with durable polymer the LEADERS trial substudy. JACC Cardiovasc Interv 2009;2(9):861-870

20 Cortese B, Micheli A, Picchi A, et al. Paclitaxel-coated balloon versus drug-eluting stent during $\mathrm{PCI}$ of small coronary vessels, a prospective randomised clinical trial. The PICCOLETO study. Heart 2010;96(16):1291-1296

21 Latib A, Colombo A, Castriota F, et al. A randomized multicenter study comparing a paclitaxel drug-eluting balloon with a paclitaxel-eluting stent in small coronary vessels: the BELLO (Balloon Elution and Late Loss Optimization) study. J Am Coll Cardiol 2012;60(24):2473-2480 
22 Maier LS, Maack C, Ritter O, Böhm M. Hotline update of clinical trials and registries presented at the German Cardiac Society meeting 2008. (PEPCAD, LokalTax, INH, German ablation registry, German device registry, DES.DE registry, DHR, Reality, SWEETHEART registry, ADMA, GERSHWIN). Clin Res Cardiol 2008;97(6):356-363

23 Lee CW, Suh J, Lee SW, et al. Factors predictive of cardiac events and restenosis after sirolimus-eluting stent implantation in small coronary arteries. Catheter Cardiovasc Interv 2007;69(6):821-825

24 Koning R, Eltchaninoff $\mathrm{H}$, Commeau P, et al; BESMART (BeStent in Small Arteries) Trial Investigators. Stent placement compared with balloon angioplasty for small coronary arteries: in-hospital and 6-month clinical and angiographic results. Circulation 2001;104(14):1604-1608

25 Moses JW, Leon MB, Popma JJ, et al; SIRIUS Investigators. Sirolimus-eluting stents versus standard stents in patients with stenosis in a native coronary artery. N Engl J Med 2003;349(14):1315-1323

26 Uddin MJ, Chowdhury AHK, Ali M, et al. Percutaneous coronary intervention $(\mathrm{PCI})$ result of 100 cases. Bangladesh Heart Journal 2003;18:109-115

27 Dan KK, Islam MN, Hossain MN, Uddin MJ, Islam AKMM. Peri-procedural outcome of small vessel coronary stenting. Bangladesh Heart Journal 2015;30(1):22-26

28 Ali MR, Haque KMHSS, Ahmed QS, Rahman M, Haque SA. Short term outcome of percutaneous transluminal angioplasty with and without stent in the treatment of coronary artery disease. Chest Heart J 2002;26:14-20

29 Rahman S, Masky A, Akanda AK, Malik F, Ahmed N. Prediction of immediate outcome of intracoronary stent implantation by lesion morphology. Bangladesh Heart J 2001;16:1-8

30 Briguori C, Sarais C, Pagnotta P, et al. In-stent restenosis in small coronary arteries: impact of strut thickness. J Am Coll Cardiol 2002;40(3):403-409
31 Moer R, Myreng Y, Mølstad P, et al. Stenting In Small Coronary Arteries (SISCA) trial. A randomized comparison between balloon angioplasty and the heparin-coated BeStent. J Am Coll Cardiol 2001;38(6):1598-1603

32 Haude M, Konorza TF, Kalnins U, et al; Heparin-COAted STents in small coronary arteries Trial Investigators. Heparin-coated stent placement for the treatment of stenoses in small coronary arteries of symptomatic patients. Circulation 2003;107(9):1265-1270

33 Grenadier E, Roguin A, Hertz I, et al. Stenting very small coronary narrowings $(<2 \mathrm{~mm}$ ) using the biocompatible phosphorylcholine-coated coronary stent. Catheter Cardiovasc Interv 2002;55(3):303-308

34 Pache J, Kastrati A, Mehilli J, et al. Intracoronary stenting and angiographic results: strut thickness effect on restenosis outcome (ISAR-STEREO-2) trial. J Am Coll Cardiol 2003;41(8):1283-1288

35 Brambilla N, Morici N, Bedogni F, et al; RISICO investigators. Thin strut chrome-cobalt stent implantation for treatment of de-novo lesions in small coronary vessels: results of the RISICO Italian Registry (Registro Italiano Mini VISION nei piccolo Vasi) utilizing the Mini VISION coronary stent platform. J Cardiovasc Med (Hagerstown) 2009;10(11):852-858

36 Turco MA, Ormiston JA, Popma JJ, et al. Reduced risk of restenosis in small vessels and reduced risk of myocardial infarction in long lesions with the new thin-strut TAXUS Liberté stent: 1 -year results from the TAXUS ATLAS program. JACC Cardiovasc Interv 2008;1(6):699-709

37 Garcia E. Randomized evaluation of the Multilink Rx Pixel coronary stent system using a pre-dilatation vs no predilation implantation strategy in the treatment of small vessels. Presented at EuroPCR, Paris, France 5/2003

38 Novel 2.0-mm Stent Promising for Super Small Coronary Vessels-Medscape. May 18, 2017 